sistema financeiro entre os países sul-americanos; a criação de linhas de crédito regionais direcionadas para o financiamento de investimentos de infra-estrutura e de operações de comércio internacional; e as recentes iniciativas do governo venezuelano em adquirir títulos da dívida pública de alguns países da América do Sul. O tema do texto é pertinente principalmente pelo fato de que, a partir da reestruturação do Mercosul, tem-se discutido, por um lado, a possibilidade de implementação de um mercado comum na América do Sul e, por outro, foi criado no final do ano passado o Banco do Sul. Em suma, as questões apresentadas pelos autores, as perspectivas em torno de uma integração mais dinâmica da América do
Sul e a criação do referido Banco constituem-se, parafraseando os autores, em "um conjunto de articulações [que podem ser] responsáveis pela integração financeira e comercial da América do Sul” (2007:326).

Concluindo, os textos, escritos por acadêmicos e pesquisadores de diferentes áreas das Ciências Sociais, apresentam uma qualificada contribuição acerca dos desafios políticos, econômicos e sociais com que se defrontam os países em desenvolvimento.

Fernando Ferrari Filho Professor Titular da UFRGS e Pesquisador do CNPq

\title{
A Era da Turbulência
}

\section{Alan Greenspan (org.)}

Rio de Janeiro: Campus

Instigante. É a primeira idéia que vem a cabeça de quem teve o prazer de ler as quase 500 páginas desta auto-biografia de um dos economistas mais importantes da atualidade. Por um lado, a leitura de "A Era da Turbulência" mostra claramente que o seu autor tem uma visão de mundo que muitos no Brasil chamariam de neoliberal. Em alguns trechos, Alan Greenspan faz uma defesa quase que apologética da economia de livre-mercado. Isso certamente irá desagradar as pessoas que acreditam que o futuro da humanidade é o socialismo. Por outro lado, o "velho maestro" é pragmático o suficiente para reconhecer não só o seu papel limitado como presidente do FED para a fase de maior prosperidade na economia dos Estados Unidos após o colapso do Sistema de Bretton Woods, como também o papel necessário da política monetária como estabilizador das economias capitalistas modernas.

Um primeiro aspecto que chama a atenção do leitor de "A Era da Turbulência" é o método de análise de Greenspan como economista. Tomando como base a discussão feita por Tony Lawson sobre a natureza da economia heterodoxa, podemos afirmar, com pouca margem para dúvida, que Greenspan é um bom economista heterodoxo. Isso porque as suas análises como consultor de investimentos na Tonwsend-Greenspan e, posteriormente, como Chairman do Federal Reserve não se baseavam na aplicação de métodos econométricos sofisticados a uma massa de dados agregados; mas sim numa análise cuidadosa das séries econômicas a nível desagregado, extraindo-se inferências das mesmas tendo como base apenas a teoria econômica a nível mais elementar e o bom-senso. Sua desconfiança dos modelos econômicos e da econometria está apoiada na idéia de que as economias capitalistas são essencialmente dinâmicas (não-ergódicas). Dessa forma, a inferência estatística tende a produzir estimativas viesadas dos parâmetros das equações estruturais dos modelos econômicos.

Essa habilidade para extrair informações de uma massa de dados econômicos com o intuito de subsidiar a tomada de decisões foi extremamente útil para a condução da política monetária norte-americana na segunda metade da década de 1990. Com efeito, Greenspan relata que na reunião do FOMC de 24/09/1996, os diretores do FED estavam bastante receosos quanto ao ritmo de crescimento da economia norte-americana. Havia entre alguns diretores a sensação de que a economia dos EUA estava crescendo rápido demais e que isso iria, mais cedo ou mais tarde, causar uma aceleração da inflação, a não ser que o FED pusesse o pé no freio por intermédio 
de aumentos preventivos da taxa básica de juros. Greenspan estava convencido que um aumento da taxa de juros não era necessário. Sua intuição era que a revolução tecnológica promovida pela Internet estava acelerando o ritmo de crescimento da produtividade do trabalho de forma que a economia americana poderia crescer mais sem gerar pressões inflacionárias.

O problema com essa hipótese, como admite o próprio Greenspan na seqüência, era o fato de que os números oficiais de crescimento da produtividade não mostravam uma aceleração do ritmo de crescimento do produto por horas trabalhadas. Uma pessoa sem as habilidades de Greenspan facilmente concluiria que não havia razões para acreditar que a economia poderia crescer a um ritmo mais forte do que no passado sem gerar pressões inflacionárias. Mas não foi isso o que aconteceu com o "velho Maestro". Para ele havia algo de errado com os números oficiais de crescimento da produtividade, pois as empresas não iriam investir grandes somas de recursos em novas tecnologias de informação se isso não aumentasse a produtividade do trabalho e, portanto, os seus lucros. Assim ele pediu ao staff técnico do FED para fazer um desdobramento detalhado setor a setor da produção por horas trabalhadas de dezenas de setores não-agrícolas. A conclusão do relatório era que, com base nos números oficiais, não teria havido aumento da produtividade no setor de serviços, pelo contrário, a eficiência nesse setor estava diminuindo. Isso era uma prova irrefutável que os números oficiais estavam errados. Não havia, portanto, bases objetivas para justificar um aumento da taxa de juros. Mas também não havia elementos objetivos para sustentar a tese contrária de que a economia norte-americana não estava crescendo a um ritmo alto demais para manter a inflação estável. O FOMC teria que tomar uma decisão às cegas, num ambiente de total incerteza. Nesse contexto, a variável fundamental no processo de tomada de decisão, como diria Keynes, é o otimismo espontâneo ou animal spirits. Foi o otimismo espontâneo de Greenspan que levou os diretores do FOMC a manter inalterada a taxa de juros naquela reunião.

Outra característica heterodoxa do pensamento econômico de Greenspan é a forma pela qual ele vê o progresso econômico no capitalismo. O crescimento de longo-prazo das economias capitalistas é originado pelo crescimento da pro- dutividade do trabalho que resulta do processo de "destruição criativa" de Schumpeter. Nesse contexto, a concorrência no capitalismo deve ser vista como um processo pelo qual as empresas inovadoras introduzem novos bens e novos processos de produção com o objetivo de sucatear as velhas tecnologias e se apoderar do mercado das empresas que não se mostrarem capazes de introduzir novos bens e novos processos produtivos. A essência do capitalismo é, portanto, a destruição do velho pelo novo.

Nesse contexto, não é surpreendente que o "velho Maestro" seja um defensor da tese de que a abundância de recursos naturais pode atrapalhar, ao invés de ajudar, o desenvolvimento econômico. Greenspan vê a assim chamada "doença holandesa" como um entrave ao desenvolvimento econômico. Isso porque a abundância de recursos naturais tende a produzir uma grande apreciação da taxa real de câmbio, a qual impede a industrialização da economia e a diversificação de sua base produtiva.

Se o processo de "destruição criativa" tende a aumentar o bem-estar econômico da sociedade ao resultar em aumentos da produtividade do trabalho; por outro lado, esse processo tende a gerar instabilidade e incerteza. O sucateamento das velhas tecnologias implica na demissão de um grande número de trabalhadores das empresas que ficaram para trás na corrida tecnológica. Nem sempre as pessoas demitidas dos "velhos setores" terão as habilidades e os perfis exigidos pelos novos postos de trabalho criados na esteira do processo de inovação. Para essas pessoas, a "destruição criativa" implica num período bastante longo de desemprego e queda de rendimentos. Mesmo os vencedores da corrida tecnológica não podem "dormir sob os louros" de sua vitória, pois em algum momento sua posição de "vencedor" será contestada pela introdução de novos produtos e novos processos. A única forma de se manter vivo ao longo desse processo é, portanto, inovar sempre. Isso gera um grande stress nas pessoas.

Nesse contexto, existiria um trade-off entre prosperidade econômica e "qualidade de vida”. A concorrência Schumpeteriana é o motor do progresso econômico no capitalismo, mas traz consigo uma dose elevada de instabilidade e imprevisibilidade para a vida das pessoas.

Esse trade-off entre prosperidade e "estabilidade pessoal" explica a existência de diversas for- 
mas de capitalismo. Algumas sociedades, como os Estados Unidos, escolhem, por razões culturais ou de qualquer outra espécie, maximizar a prosperidade econômica. Dessa forma, os governos não oferecem quase nenhum tipo de proteção contra os efeitos deletérios da destruição criativa. Os setores que ficarem para trás na corrida tecnológica, como as siderúrgicas americanas face à concorrência de suas congêneres japonesas, são simplesmente deixados para trás e morrem. O nível de seguro desemprego tende a ser baixo nessas economias, de maneira que os trabalhadores têm pouca ou nenhuma proteção contra os efeitos da "destruição criativa" sobre os seus empregos. A maioria das sociedades européias, por sua vez, escolheu um modelo híbrido no qual os governos "protegem parcelas de suas populações contra o que consideram árduas pressões competitivas” (p. 259). O resultado desse modelo híbrido é, na visão de Greenspan, uma sociedade menos dinâmica e, portanto, menos próspera. Trata-se de uma questão de escolha, nenhuma alternativa é intrinsicamente superior a outra, tudo depende das preferências sociais.

Um campo no qual Greenspan se mostra surpreendentemente ortodoxo é na sua visão a respeito do papel da política monetária. Quando ele discorre sobre o papel da política monetária na promoção de um crescimento econômico robusto e estável, ele é bastante enfático na defesa da tese de que o papel do FED, ou de qualquer outro banco central, para a promoção do crescimento econômico é a manutenção da estabilidade de preços. Além disso, para que o Banco Central desempenhe adequadamente a sua função de "guardião da estabilidade de preços” é necessário que ele seja independente de forma a ficar isolado de pressões políticas.

A sua ortodoxia nesse campo fica também bastante clara quando ele disserta sobre as causas do crescimento acelerado da economia norteamericana durante a administração Clinton. $\mathrm{O}$ "Velho Maestro", ao contrário do que se poderia esperar, não atribui essa performance a uma condução bem feita da política monetária por parte do FED. Para Greenspan, a causa do crescimento acelerado com inflação baixa vivenciados nos Estados Unidos na década de 1990 é essencialmente não-monetária e deve ser buscada na difusão das novas tecnologias de informação, as quais permitiram um uso mais eficiente dos recursos disponíveis, aumentando assim a produtividade do trabalho (pp. 162-163). Esse aumento da produtividade permitiu uma redução da NAIRU, ou seja, da taxa de desemprego compatível com uma inflação constante ao longo do tempo. Nesse contexto, o papel do FED foi simplesmente o de facilitar o ajuste da economia a um nível de desemprego de equilíbrio mais baixo por intermédio de uma política monetária expansionista.

Fatores exógenos a economia norte-americana também contribuíram, na visão de Greenspan, para o crescimento acelerado com inflação baixa durante a administração Clinton. O primeiro fator foi a globalização e a queda do comunismo soviético. Esses dois elementos implicaram no deslocamento de grandes massas de trabalhadores para os mercados competitivos, gerando taxas de inflação salarial mais baixas e, por conseguinte, diminuindo a taxa de desemprego compatível com a estabilidade de preços. O segundo fator foi a aceleração do crescimento econômico dos países em desenvolvimento, principalmente no Sudeste Asiático, o que implicou numa redistribuição de renda a nível mundial dos países desenvolvidos, com taxas de poupança mais baixas, para os países em desenvolvimento que possuem taxas de poupança mais altas. Essa redistribuição de renda implicou, portanto, num aumento da taxa média de poupança a nível mundial, exercendo assim uma pressão baixista sobre a taxa real de juros de longo-prazo em todos os países do mundo. A redução da taxa real de juros de longo-prazo não só estimulou o investimento em capital fixo nos países desenvolvidos, principalmente nos Estados Unidos, aumentando assim o ritmo de crescimento econômico; como ainda induziu um processo cumulativo de aumento dos preços das ações e dos imóveis. Em outras palavras, a "exuberância irracional" do final da década de 1990 foi causada, entre outras coisas, por um excesso de poupança a nível mundial.

Um outro aspecto interessante a respeito do pensamento do Greenspan sobre a política monetária é a sua concepção extremamente original a respeito do processo de tomada de decisão a respeito do valor da taxa básica de juros. Aqui vemos outra vez o Greenspan heterodoxo em cena. A teoria da política monetária de livros-texto estabelece que a taxa básica de juros deve ser fixada de tal forma que, no cenário padrão dos modelos de simulação, a taxa de inflação convirja para a meta de inflação de longo-prazo perseguida (explicita ou implicitamente) pela autoridade monetária. Greenspan é um severo crítico desse 
procedimento. Sua abordagem para o problema se baseia no método do balanceamento de riscos. Com base nesse método, a autoridade monetária deve levar em conta não só o cenário mais provável, como também aqueles cenários com baixa probabilidade de ocorrência, mas cuja realização implique em custos econômicos muito grandes para a sociedade.

Em matéria de política fiscal, não se pode ter dúvidas quanto a ortodoxia do ex-chairman do FED. Ele é um defensor entusiasta da tese de que os déficits fiscais prejudicam o crescimento de longo-prazo. $\mathrm{O}$ seu argumento, contudo, não é simplório. Ele está perfeitamente ciente de que as taxas de juros de longo-prazo não são determinadas pelos fluxos de demanda e oferta de obrigações do tesouro, mas pela demanda e oferta das mesmas como estoque. Dessa forma, um aumento do déficit público teria um impacto negligenciável sobre a taxa de juros de longo-prazo, uma vez que os fluxos de novas emissões de obrigações são uma pequena parte do estoque existente desse tipo de ativos. O seu argumento é que um aumento do déficit público hoje, ao sinalizar para os investidores uma seqüência de déficits fiscais mais altos no futuro, irá gerar um aumento da taxa de juros de longo-prazo, com efeitos negativos sobre a acumulação de capital e o crescimento econômico (p.230). Nesse contexto, a política fiscal ótima é operar com déficit fiscal igual a zero. Para tanto, é necessária a introdução de regras fiscais claras que impeçam o governo de criar despesas sem a contra-partida de aumento de receitas tributárias.

Sua ortodoxia também fica bem clara quan- do ele disserta sobre os requisitos institucionais para um capitalismo bem sucedido, parafraseando o comentário de Keynes a Commons. Na visão de Greenspan, o crescimento econômico será maximizado num ambiente institucional no qual i) a economia esteja aberta a concorrência global por intermédio do comércio internacional; ii) haja uma clara definição e defesa dos direitos de propriedade; e iii) os formuladores de política econômica tenham sido bem sucedidos na tarefa de implementar as medidas necessárias para a estabilidade macroeconômica (pp. 242-243).

A visão política de Greenspan deve desagradar a muitos dos leitores de "A Era da Turbulência". O "Velho Maestro" afirma várias vezes que o capitalismo de mercado é a melhor forma de organização das sociedades humanas, pois proporciona o maior bem-estar econômico no longo-prazo. A democracia é funcional ao capitalismo porque permite que as tensões acumuladas pelo jogo da "destruição criativa" sejam liberadas sem ser por intermédio de forças disruptivas, ou seja, por intermédio de revoluções que ameacem o direito de propriedade. Ele também é um severo crítico do Estado do Bem-Estar Social. Para Greenspan, o welfare-state reduz a eficiência econômica e o impulso ao progresso porque desestimula os indivíduos a competir e assumir riscos; embora ele reconheça que o mesmo atende a uma necessidade básica dos seres humanos que é a estabilidade.

José Luis Oreiro

Professor do Departamento de Economia da UFPR e pesquisador do CNPq. 